tion, the less room there is for differences of opinion on what is wanted in the answer. Finally, I must stress that, although in OT ranking order is exact, there is still the question of where to put both the pass-fail and any inter-class barriers.

Certain disadvantages of OT should be mentioned.

(1) Setting can be as time-consuming as machine-marking is simple. Spread must continuously be checked; the position of the right answer must be varied; distractors must be both plausible and of similar plausibility. Finally, in the marking, there must be a penalty for guessing.

(2) Especially in SOT, there is only one right answer. Especially in science, a particular point may be very debatable and anything but simple. Like programmed learning (get the sole accepted answer before going on to the next step), OT can inject an unhealthy authoritarianism and superficiality.

(3) In general, both knowledge of facts and ability to apply them should be tested. Ability to choose relevant facts and marshall them in logical order can be tested only by the essay (or orally). Even if there is a problem in an OT paper, one can know only what answer has been derived (or, in SOT, selected). What is much more important, how this was deduced can never be known.

(4) At times OT can test even factual knowledge only in a very cumbersome manner if at all. The sensible test of a definition is to ask for it-which may be beyond the scope of an ROT question ; ability to translate (knowledge of vocabulary and grammar) can be tested only by translation; knowledge of phonetics is best tested by writing a passage in phonetics; one of the best tests of familiarity with literature is the question "Assign to context: ...."

(5) Such a question as "With an example for each consonant mentioned, give an account of Grimm's Law", although an essay question is not only about the only one that could be asked on the Law, but is also quite objective. All these examples are of areas in which the "essay" question is superior to the OT question in testing factual knowledge and can be marked as accurately as the latter.

OT is not to be condemned bell, book and candle. All methods of examining have their merits and demerits. Since Dr Cox's paper leaned heavily towards OT, it is only right that my reply should emphasize the opposite case.

Yours faithfully,

$$
\text { P. A. Ongley }
$$

Department of Chemistry,

University of Aston,

Gosta Green,

Birmingham B4 ET18

\section{Cancer Research}

SIR,-Dr John Paul comments (Nature, 240,$492 ; 1972$ ) on your correspondent's report entitled "Lord Zuckerman Defends his Position" (Nature, 240, 247 ; 1972) and refers to what I said at the meeting of the British Association for Cancer Research.

I spoke about the development of the four new oncological centres, made a plea for closer integration of work being done in laboratories, in clinics and in the field and asked for greater emphasis on the flow of ideas from clinic to laboratory. I also asked some questions about accountability, effectiveness and efficiency, suggesting that in the context of the human cancer problem it was no less necessary and no more invidious to ask for assessment of the relevance and value of work done at subcellular level than it was at patient or community levels.

Dr Paul complains that in advocating greater emphasis on clinically oriented research, I was wrong in claiming that supracellular biologists had made a greater contribution to the welfare of the cancer patient than molecular biologists. The passage from my talk referred to was as follows:

"The mere asking of such controversial questions has been taken by some subcellular biologists to be a denial of the importance of their work, rather than an encouragement of the work of the supracellular biologists who have to date made a far greater contribution to the welfare of the cancer patient. 'Fundamental cancer research' has yet to match the long record of success of clinical and epidemiological investigations to which we owe so much in cancer prevention, detection and treatment. Hormone control of cancer arose from the observations of a surgeon, and both radiotherapy and chemotherapy had their origins in observations of their effects on man. Each clinical discovery has led to the creation of new research departments to fill important feedback functions. Successful preventive measures have stemmed in the case of mouth cancer from the work of the dental profession, and in lung cancer from that of the epidemiologists and statisticians. If cancer research is to advance more quickly toward practical control of the human disease processes involved, rather than make progress in some other if perhaps equally important function, then those engaged must have a close contact with the clinical scene and derive inspiration from it."

Of course it is Dr Paul who is wrong. His suggestion that cancer chemotherapy stemmed from molecular biology is quite untenable; it stemmed from clinical observation, its increasingly effective combinations developed from clinical practice and biochemistry was brought in later and most helpfully to support, to develop and to attempt to account for the success achieved.

Arguments about the merits of research at different biological levels are unprofitable since we need to understand the mechanisms of disordered growth at all levels of organization. I was discussing emphasis and relative effort. I am glad to see that Dr Paul, though regarding me as "puckish" when I am serious, also regards me as "reasonable" in holding the view that distinctions based on the value of work at different biological levels are pointless and that coordination of work at all levels is essential.

$$
\begin{aligned}
& \text { Yours faithfully, } \\
& \text { D. W. SMITHERs }
\end{aligned}
$$

The Royal Marsden Hospital,

London and Surrey,

Fulham Road,

London SW3 6JJ

\section{Acupuncture}

SiR,-There has been much recent interest in acupuncture, but as early as 1823 a treatise on the subject was published in England. In the December issue of The British Critic, 668 (1823), an unnamed reviewer discusses three new books. Each seeks to introduce a foreign method of medical treatment, and the only one which the reviewer feels is "deserving of serious consideration" is :

"Art XII. A Treatise on Acupuncturation; being a Description of a Surgical Operation originally peculiar to the Japanese and Chinese and by them denominated Zin-King, now introduced into European Practice, with Directions for its Performance, and Cases illustrating its Success. By James Morss Churchill, Member of the Royal College of Surgeons in London. 8 vo. 86 pp. 4s. Simpkin and Marshall. 1823."

Churchill's book receives the bulk of critical attention, while the other two, a treatise on Fumigating Baths (from France) and a treatise on Shampooing (from India), receive minimal attention as they are thought to be "of little worth".

In several long passages quoted from Churchill's book, the technique of acupuncture is described, and a whole range of maladies for which it had proved useful are mentioned. Churchill cites in particular two cases in which he himself had successfully performed acupuncture. The first was a woman suffering from rheumatic pain, the other was "William Morgan, a young man in the employment of a timber merchant". The latter had strained 
himself lifting heavy timbers, and two consecutive treatments of acupuncture, one by a needle "passed to the depth of an inch on either side of the spine", relieved the pain.

In addition, Churchill was aware that "acupuncturation" was practised elsewhere and cites several French doctors as having reported success with acupuncture. Also, a Dr Bretonneau, "physician to the 'Hospital General' of Paris, has made a number of experiments on puppies". These prove that "the Cerebrum, the Cerebellum, the Heart, the Lungs, the Stomach, \&c. may be penetrated without occasioning the least pain or inconvenience".

Ranging further afield, Churchill also reports a practice among American Indians in which a number of specially constructed arrows (i.e., for shallow penetration) are shot into the patient who is standing in a river. However, he concludes that this is not acupuncturation, a bloodless procedure, but is actually a form of bloodletting.

Churchill also discusses the two kinds of special gold or silver needles which the Japanese used for acupuncture. These were made only by expert artists specially licensed by the Emperor. Depending upon their design, the needles were either twisted into the flesh by hand or were driven in by a special leather-covered hammer.

The unknown reviewer, with tonguein-cheek, suggests that such medical advances might cure the ills of the literary world. He recommends "regular quarantine fumigation" for Lord Byron and Carlisle, shampooing for $\mathrm{Mr}$ Wilberforce and "the secondary Scotch novellists", and acupuncturation for Joseph Hume and Henry Brougham.

Evidently, mention of or allusions to acupuncture does not appear in early or mid 19th-century popular writing. Certainly it would have been mentioned had it become at all fashionable. Churchill recommends it (as it is touted by some today) as a cure for many ills. Although a surgeon, he seems to have missed its possible use as an anaesthetic during surgery. One wonders why, if it was indeed so effective, acupuncture was not accepted in England or France and retained by the Japanese?

\section{Yours faithfully,}

MAUREen LIPPERT

ERNEST L. LIPPERT, JUN.

2228 Barrington Drive,

Toledo, Ohio 43606

\section{Anglo-Soviet Exchange}

SIR,-Your leader entitled "AngloSoviet Science - Hopes Revived" (Nature, 239, 482; 1972) expresses the hope that the plans for cooperation in science and technology between the UK and the USSR will be revitalized following the recent visit of a delegation from the Soviet State Committee for Science and Technology. You contrast the failure to implement article 3 of the 1968 agreement which provides for exchange visits by applied scientists and technologists with the success of the Royal Society/Soviet Academy of Sciences arrangement. May I draw your attention to the Agreement on Relations in the Scientific, Educational and Cultural Fields which, in addition to embracing the Royal Society's Agreement, includes provision for exchanges in science and technology with Academy and non-Academy Institutes and Universities. These are administered by the British Council and represent a substantial inter-movement of scientists, both for short-term "familiarization" visits and for longer-term attachments for postgraduate study and research. Sixty-seven Soviet scientists came to the UK in 1971 (56 in 1970), while seventeen British scientists visited the USSR (twenty-four in 1970). The reason for the apparent imbalance is that younger Soviet scientists are particularly keen to pursue postgraduate studies here, whereas the attraction for British postgraduates is greater in fields other than science. Both countries contribute to the cost of the exchanges which provide an opportunity for scientists in a wide range of disciplines to meet and gain research experience.

Yours faithfully,

The British Council,

$$
\text { W. A. BARR }
$$

Lonsdale Chambers,

27 Chancery Lane,

London WC $2 A 1 P J$

\section{Algae and Protozoa}

SiR,-A sample survey of the literature on algae and protozoa has confirmed the impression that authors do not always give adequate reference to the strains used in work involving cultures.

The sample used was the 1971 issues of fourteen journals taken at this establishment which publish original work on algae and protozoa. Papers dealing with fossils, larger seaweeds and organisms not so far cultured were excluded.

Minimum adequate reference is considered to be the designation of the culture together with, where appropriate, indication of the source collection, for example, CCAP $211 / 8 \mathrm{~d}$ or Göttingen $11 / 6$. A more complete reference would give also the name of the isolator and the date of isolation, but this information is usually available in the list published by the collection.

The survey shows that over three- quarters (153 out of 204) of the authors used cultures when this was possible. It also shows that well over half of the users (eighty-nine out of 153) gave inadequate or no reference to the cultures used. This is most unsatisfactory, especially when one considers the rigid insistence by authors and editors on proper bibliographic references.

References to specific names and a collection, for example, "Chlamydomonas globosa from CCAP" are not satisfactory as there may be now, or in the future, more than one strain fitting that description. Also, taxonomic names are liable to revision while strain designation should be immutable. References such as "Tetrahymena pyriformis 'W' Strain" are inadequate without mention of the source. It has recently been shown by isozymal tests that strains of this species from different sources but with the same designation may differ, while differently designated strains may be identical. The cause of this confusion presumably lies in mislabelling and failure to record the origin of stocks used. In one paper there was a serious orthographic error in a strain designation.

Among the advantages of using properly documented strains are (a) that the work can be repeated or compared with other work on the same strain, and (b) that comparison of different strains of a species or of different species of a genus enables the significance of the particular characters to be assessed. Too often one sees a general statement about a species made from evidence derived from only one strain.

Wherever possible, cultures of new taxa or new strains used in important research should be deposited in at least one major collection. It is also of great value to a culture collection to receive reprints of work done with its cultures.

\section{Yours faithfully,}

\section{E. A. George}

The Culture Centre of Algae and

Protozoa,

36 Storey's Way,

Cambridge $C B 3$ ODT

\section{Potato Blight Teratogen}

SIR,-The most recent and dramatic hypothesis to be pronounced about the aetiology of the neural tube malformations, anencephaly and spina bifida cystica, is that published earlier this year by Renwick (Brit. J. Prev. Soc. Med., 26, 67; 1972), where it is suggested that the damaged or diseased and especially the blight-diseased or even blight-resistant potato is in some way related. Renwick cites the time/ space relationship between secular changes in malformation rates and the severity of blight in West Scotland, the 